\title{
Technique and feasibility of a dual staining method for estrogen receptors and AgNORs
}

\author{
Lukas Günther $^{\mathrm{a}, *}$ and Peter Hufnagl ${ }^{\mathrm{b}}$ \\ ${ }^{a}$ Department of Surgery, University of Heidelberg, \\ Heidelberg, Germany \\ b Institute of Pathology, Charité Hospital, \\ Humboldt-University Berlin, Germany
}

Received 2 November 1999

Accepted 11 September 2000

A new staining method for dual demonstration of Estrogen receptors (ER) and argyrophilc Nucleolus-Organizer Regions (AgNORs) was developed. To rule out possible reciprocal effects, serial slides of 10 invasive ductale breast cancers were stained with either the single staining method or the simultaneous ER/AgNOR-staining method and investigated comparatively. By measuring the slides with the image analysis system AMBA, reciprocal effects could be excluded. It was proven that dual staining of both markers results in a reproducible and specific staining result. We concluded that it is justified to measure AgNORs in immunohistochemically stained cells.

Keywords: AgNORs, estrogen receptors, immunohistochemistry, breast cancer, dual staining, reproducibility

\section{Introduction}

The combination of immunohistochemical methods and other staining techniques for measuring different malignancy-associated parameters in the same cell is a new focus of pathohistological research. For combined cellular investigation of AgNORs and estrogen receptors, a special staining procedure for dual demonstration of AgNORs and ER in the same histological slide is required. Since reciprocal influences cannot be excluded en passant, the reproducibility of a dual

\footnotetext{
*Corresponding author: Lukas Günther, M.D., Immunobiology Research Center, Beth Israel Deaconess Medical Center, Harvard Medical School, 99 Brookline Ave., \#370, Boston, MA 02215, USA.
}

staining technique has to be proved. This study investigates if the simultaneous staining effects the staining and measuring results (percentage of ER-positive cells; AgNOR number and area). The central question is whether AgNOR measurements in immunhistochemically stained cells are reproducible and comparable to measurements in single stained specimen.

\section{Material and methods}

Tissue of 10 invasive ductal breast cancers was used. Five cases were negative for estrogen receptors, the other 5 were ER-positive. The cancer tissue was routinely fixed in formalin $10 \%$ and embedded in paraffin. Slides of $3 \mu \mathrm{m}$ thickness were produced. For dual demonstration of estrogen receptors and AgNORs, the slides were firstly stained for ER and in a second step for AgNORs.

\subsection{Estrogen receptor staining}

After deparaffinisation (30 $\mathrm{min}$ ) and hydration in graded alcohols slides were autoclaved for $5 \mathrm{~min}$ in citric acid buffer $(\mathrm{pH}=6.0)$. Afterwards the slides were incubated with the primary antibody (estrogen receptor monoclonal antibody Nr. 1344 by Immunotech; dilution 1 : 50). DAKO LSAB2 ${ }^{\circledR}$ Kit K 0674 (biotinylated secondary antibody and Streptavidine/Alkaline Phosphatase) was used as detection system and SIGMA FAST $^{\circledR}$ Fast Red TR/Naphtol AS-MX as chromogene.

Since paraffin residues increase non-specific background staining, a thorough cleaning of the slides is necessary. The $\mathrm{pH}$ level of the Citric acid buffer has to be exactly 6.0 because even small deviations affect the staining result. The slides must not dry up during the preparation and have to be incubated in a humid chamber at $37^{\circ} \mathrm{C}$. The antibody solution has always to exceed the section edges. Otherwise, local drying-up effects ("edge effects") causes a higher level of background staining. 


\subsection{AgNOR staining}

To maintain a reproducible staining result standardization of the staining and measuring process according to the guidelines of the "International Committee on AgNOR-quantification" [1] was guaranteed. After preparing the staining solution $\left(5 \mathrm{~g} \mathrm{AgNO}_{3} / 20 \mathrm{ml}\right.$ aqua bidest with $200 \mathrm{mg}$ gelatin/10 $\mathrm{ml} 1 \% \mathrm{HCOOH}$ ), the slides were incubated at room temperature in a dark environment for exactly $30 \mathrm{~min}$.

\subsection{Image analysis and measuring procedure}

The image analysis system AMBA which was developed at the Laboratory for Automated Image Analysis at the Institute of Pathology, University Hospital Charité, Berlin, was used for the reproducibility investigations.

To rule out possible reciprocal staining effects, 3 serial slides of 10 invasive ductal breast carcinomas (5 ER-positive and 5 ER-negative cases) were stained for $\mathrm{ER}$ or $\mathrm{AgNOR}$ or $\mathrm{ER} / \mathrm{AgNOR}$ and investigated comparatively.

Firstly, one slide of each case was stained with the AgNOR method only. Another slide was stained for ER and AgNORs. A set of 200 nuclei per slide was measured by means of the program "norcolor" (objective: $40 \times$; numerical aperture: 0.7$)$. It was measured in corresponding image sections. AgNOR number per nucleus (NORNB) and total AgNOR area per nucleus (NORAREA) were evaluated.

Secondly, one slide was stained for ER, a different one stained for ER/AgNORs. For quantification of the ER staining result, the number of ER-positive nuclei per image section was counted in a set of 6 corresponding image sections (magnification $\times 200$; objective: $40 \times$; numerical aperture: 0.7$)$. Counting of all marked cells per image section (mean $=355$ cells/image section) was done semiautomatically by means of a special counting program that offers interactive object counting within microscopic images.

\section{Results}

ER positive nuclei were stained red. In contrast ER-negative nuclei appear light yellow. The yellowish color is an artificial result of the silver staining technique. Even though no counterstaining was performed, ER-negative cells are visible and measurable. In ER-

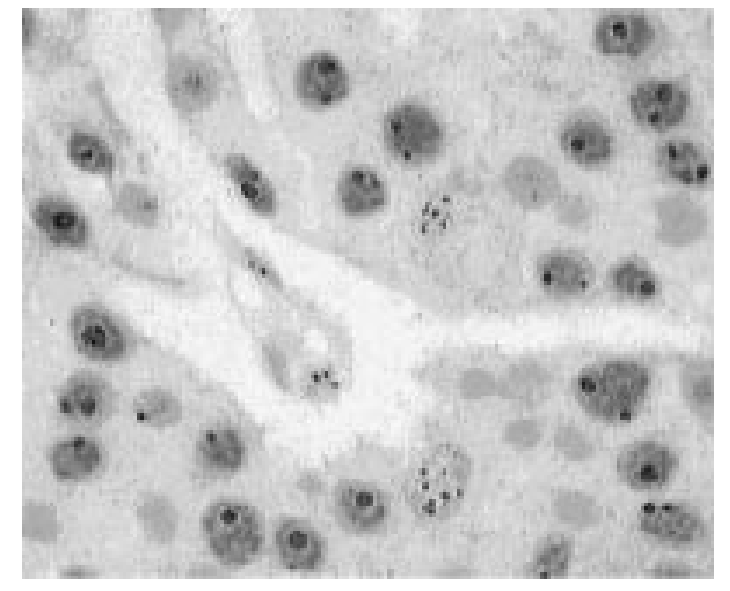

Fig. 1. Cells of invasive ductal breast cancer (G2). Dual staining for ER and AgNORs (objective $40 \times$ ).

positive as well as in ER-negative nuclei, AgNORs are visible as black-brownish dot-like structures (Fig. 1).

When the ER staining is carried out firstly a severe loss of ER-staining sensitivity was noticed. When the ER staining is done after AgNOR reaction, no similar effects were observed. The AgNOR staining itself was not influenced by the staining sequence.

The putative effect of additional ER staining on the number and area of AgNORs was investigated. A high correlation between the AgNOR number per nucleus in only AgNOR-stained and ER/AgNOR-stained nuclei was found (Fig. 2). Similar results were obtained by investigation of total AgNOR area (Fig. 3). Comparing AgNOR number per nucleus and total AgNOR area per nucleus in single AgNOR-stained and ER/AgNORstained nuclei no difference was found (Table 1). It is concluded that additional ER staining has no effect on AgNOR visualisation.

Furthermore, it had to be determined if additional AgNOR staining influences ER positivity. In all five ER negative cases neither in the only ER-staining nor in the ER/AgNOR dual staining ER positive nuclei could be detected. It can be concluded that ER/AgNOR staining does not increase ER-staining intensity.

The proof of independence of the ER-staining from the effects of AgNOR staining could be obtained by correlation of total number of ER-positive cells within 6 image sections (one image section equals $105 \times 240 \mu \mathrm{m}$ on the slide) in single ER-stained and ER/AgNOR-stained specimen ( $r=0.942)$. Obviously, the same tumor cells are stained in single ER staining and ER/AgNOR staining. It can be deducted that the AgNOR reaction does not affect the ER-staining. 


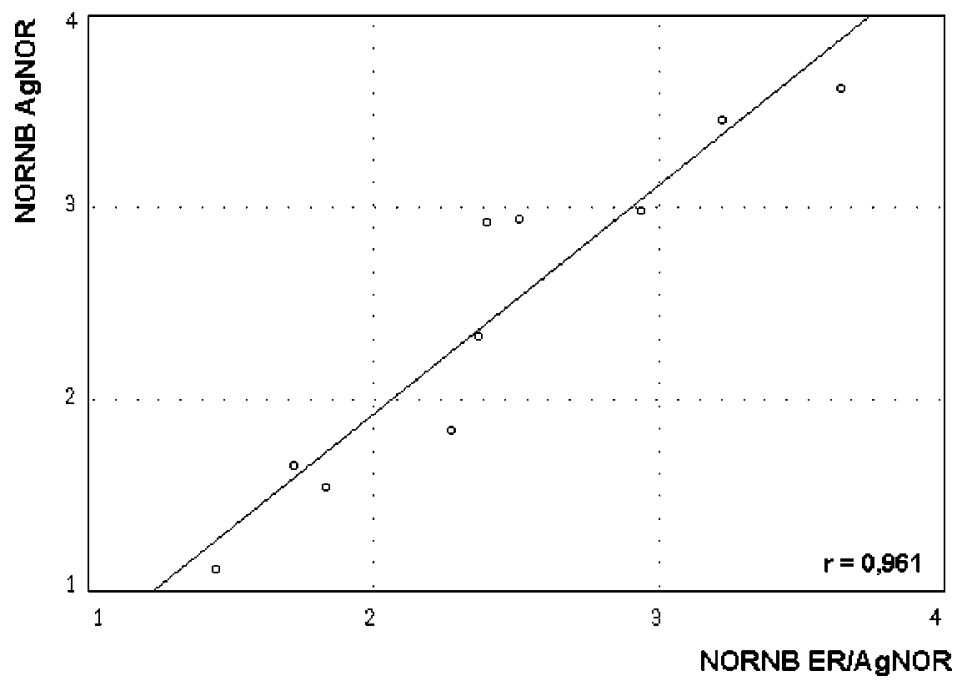

Fig. 2. Correlation of the mean AgNOR number per nucleus in single AgNOR stained cells (NORNB AgNOR) and ER/AgNOR stained cells (NORNB ER/AgNOR). The circles represent 10 invasive ductal breast cancers (5 ER-positive and 5 ER-negative cases).

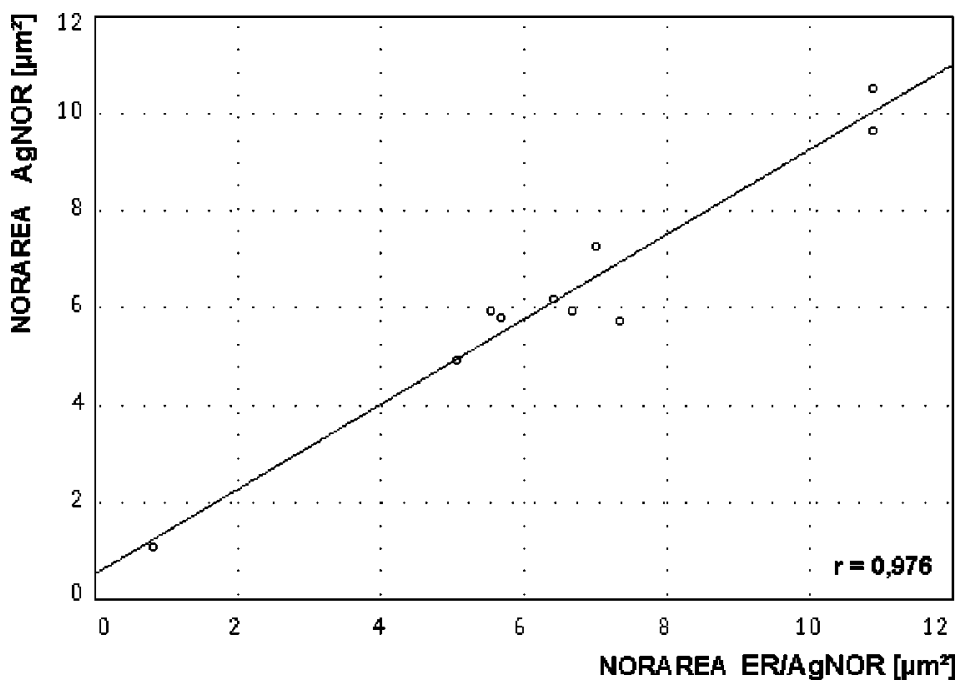

Fig. 3. Correlation of the total AgNOR area per nucleus in single AgNOR stained cells (NORAREA AgNOR) and ER/AgNOR stained cells (NORAREA ER/AgNOR). The circles represent 10 invasive ductal breast cancers (5 ER-positive and 5 ER-negative cases).

It could be proved that neither the ER staining affects the AgNOR visualisation nor the AgNOR method has any influence on the ER marking.

\section{Discussion}

The fixing and embedding process has various consequences for the tissue. While there is a better histomorphological aspect compared to frozen sections, there is also a loss of sensitivity for immunohistochem- ical methods. The cause seems to be a change in the surface-structure of the epitopes. A similar process was found in the AgNOR staining procedure. Silver staining of paraffin sections is fundamentally weaker than those of frozen sections. Different studies describe approaches for the unmasking of alterated proteins by autoclaving. These methods were independently published for immunohistochemistry [2] as well as for AgNOR reaction [3]. Because antigen retrieval by autoclaving is necessary for both staining methods, this step was carried out only once at the beginning of the staining procedure. 
Table 1

AgNOR number per nucleus (NORNB) and total AgNOR area per nucleus (NORAREA) $\left[\mu \mathrm{m}^{2}\right]$ in single AgNOR and ER/AgNOR stained slides

\begin{tabular}{|c|c|c|c|c|c|c|}
\hline \multirow[t]{2}{*}{$\mathrm{Nr}$. } & \multicolumn{2}{|c|}{$\begin{array}{l}\text { AgNOR number per } \\
\text { nucleus (NORNB) }\end{array}$} & \multirow[t]{2}{*}{ Difference } & \multicolumn{2}{|c|}{$\begin{array}{c}\text { AgNOR area per } \\
\text { nucleus (NORAREA) }\end{array}$} & \multirow[t]{2}{*}{ Difference } \\
\hline & $\begin{array}{l}\text { AgNOR- } \\
\text { staining }\end{array}$ & $\begin{array}{c}\text { ER/AgNOR } \\
\text { staining }\end{array}$ & & $\begin{array}{l}\text { AgNOR- } \\
\text { staining }\end{array}$ & $\begin{array}{c}\text { ER/AgNOR } \\
\text { staining }\end{array}$ & \\
\hline 1 & 1.83 & 1.55 & 0.28 & 4.93 & 5.00 & -0.07 \\
\hline 2 & 1.72 & 1.65 & 0.07 & 5.80 & 5.66 & 0.14 \\
\hline 3 & 2.51 & 2.93 & -0.42 & 5.73 & 7.33 & 1.60 \\
\hline 4 & 3.63 & 3.62 & 0.01 & 5.93 & 5.53 & 0.40 \\
\hline 5 & 1.45 & 1.11 & 0.34 & 1.06 & 0.80 & 0.26 \\
\hline 6 & 2.39 & 2.92 & -0.53 & 9.66 & 10.86 & -1.20 \\
\hline 7 & 2.94 & 2.99 & -0.05 & 10.53 & 10.68 & -0.15 \\
\hline 8 & 2.27 & 1.84 & 0.43 & 7.26 & 7.00 & 0.26 \\
\hline 9 & 2.36 & 2.33 & 0.03 & 6.20 & 6.40 & -0.20 \\
\hline 10 & 3.22 & 3.46 & -0.24 & 5.93 & 6.66 & -0.73 \\
\hline mean & 2.43 & 2.44 & -0.008 & 6.30 & 6.59 & 0.031 \\
\hline
\end{tabular}

Munakata et al. [4] tried to establish a dual staining method for Ki-67/AgNORs. In dual stained cells total AgNOR area per nucleus was clearly higher. No significant difference was found in the AgNOR number. For unmasking $\mathrm{Ki}-67$ proteins microwave radiation was used. This approach was used for Ki-67/AgNOR staining but not for only AgNOR-stained slides. It was concluded that microwave treatment affects the AgNOR staining. Today, it is known that any kind of antigen retrieval increases the sensitivity of the AgNOR method as well. Therefore autoclaving of the slides is part of the standard staining scheme today. When the same unmasking technique was used in a standardised scheme in dually stained slides as well as in individual AgNOR-marked slides, no differences regarding AgNOR number and area could be found.

Lorenzato et al. [5] recently described a doublestaining technique for AgNORs and MIB-1 in breast cancer for measuring AgNORs in MIB-1-positive and negative cells. The MIB-1 antibody was FITC-labelled in order to prevent thresholding and segmentation problems. Consequently, slides have to be stored at $20^{\circ} \mathrm{C}$ and have to be analysed within a short interval. However, in our method the staining result was permanently stable.

Tomobe et al. [6] applied a dual-labelling technique for AgNORs and MIB-1 in superficial bladder tumors, but quantified both markers separately and correlated the results. We consider the outstanding feature of a double-staining method to provide insight in the connections between two markers on the cellular level. By simply correlating AgNOR counts and labelling indexes potentially useful information might be lost.
In summary, it could be proved that there are no reciprocal affects of the single staining methods. The simultaneous staining of ER and AgNORs leads to a reproducible and specific staining result. We concluded that measuring AgNORs in immunhistochemically marked nuclei is methodologically justified.

\section{References}

[1] D. Öfner, M. Aubele, S. Biesterfeld et al., Guidelines of AgNOR quantitation: first update, Virchows Archiv 427 (1995), 341.

[2] B. Bier, A. Bankfalvi, L. Grote, S. Blasius and D. Ofner, Wet autoclave pretreatment for immunhistochemical demonstration of oestrogen receptors in routinely processed breast carcinoma tissue, Histochem. J. 27 (1995), 148-154.

[3] D. Öfner, A. Bankfalvi, K. Riehemann, B. Bier, W. Bocker and K.W. Schmidt, Wet autoclave pretreatment improves the visualization of silver-stained nucleolar organizer-region-associated proteins in routinely formalin-fixed and paraffin-embedded tissues, Mod. Pathol. 7 (1994), 946-950.

[4] S. Munakata and J.B. Hendricks, A multilabeling technique for simultaneous demonstration and quantitation of Ki-67 and nucleolar organizer regions (AgNORs) in paraffin-embedded tissue, J. Histochem. Cytochem. 42 (1994), 789-793.

[5] M. Lorenzato, P. Abboud, C. Lechki, F. Browarnyi, M.F.O. O'Donohue, D. Ploton and J.J. Adnet, Proliferation assessment in breast cancer: a double-staining technique for AgNOR quantification in MIB-1 positive cells especially adapted for image cytometry, Micron 31 (2000), 151-159.

[6] M. Tomobe, T. Shimazui, K. Uchida, S. Hinotsu and H. Akaza, Argyrophilic nucleolar organizer region in proliferating cell has a predictive value for local recurrence in superficial bladder tumor, J. Urol. 162 (1999), 63-68. 


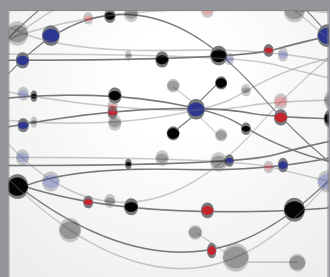

The Scientific World Journal
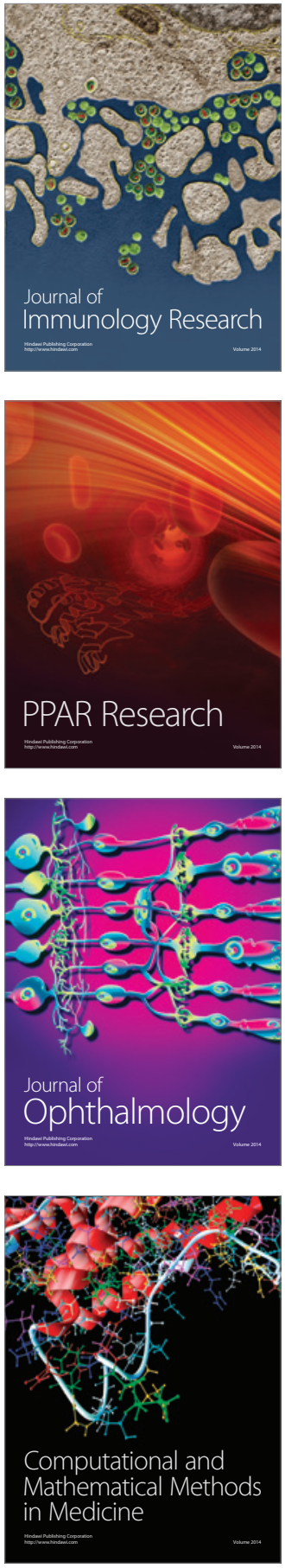

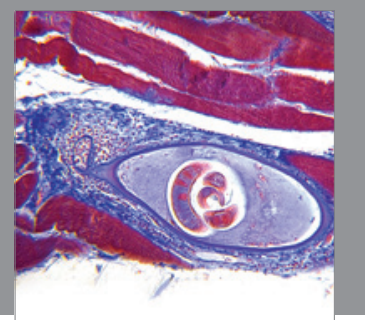

Gastroenterology

Research and Practice
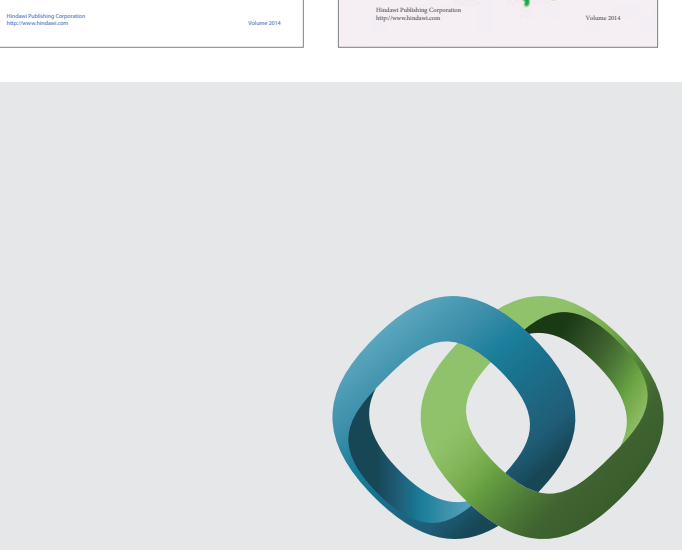

\section{Hindawi}

Submit your manuscripts at

http://www.hindawi.com
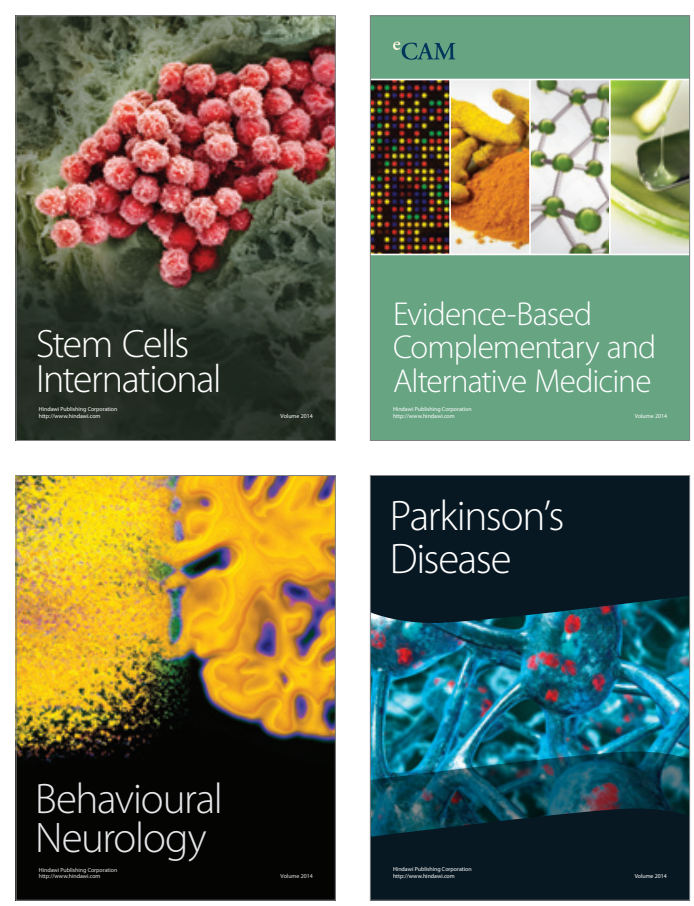

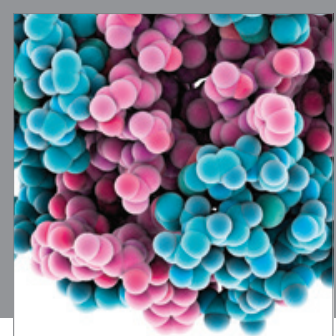

Journal of
Diabetes Research

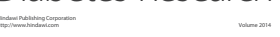

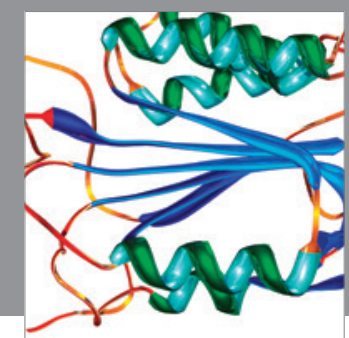

Disease Markers
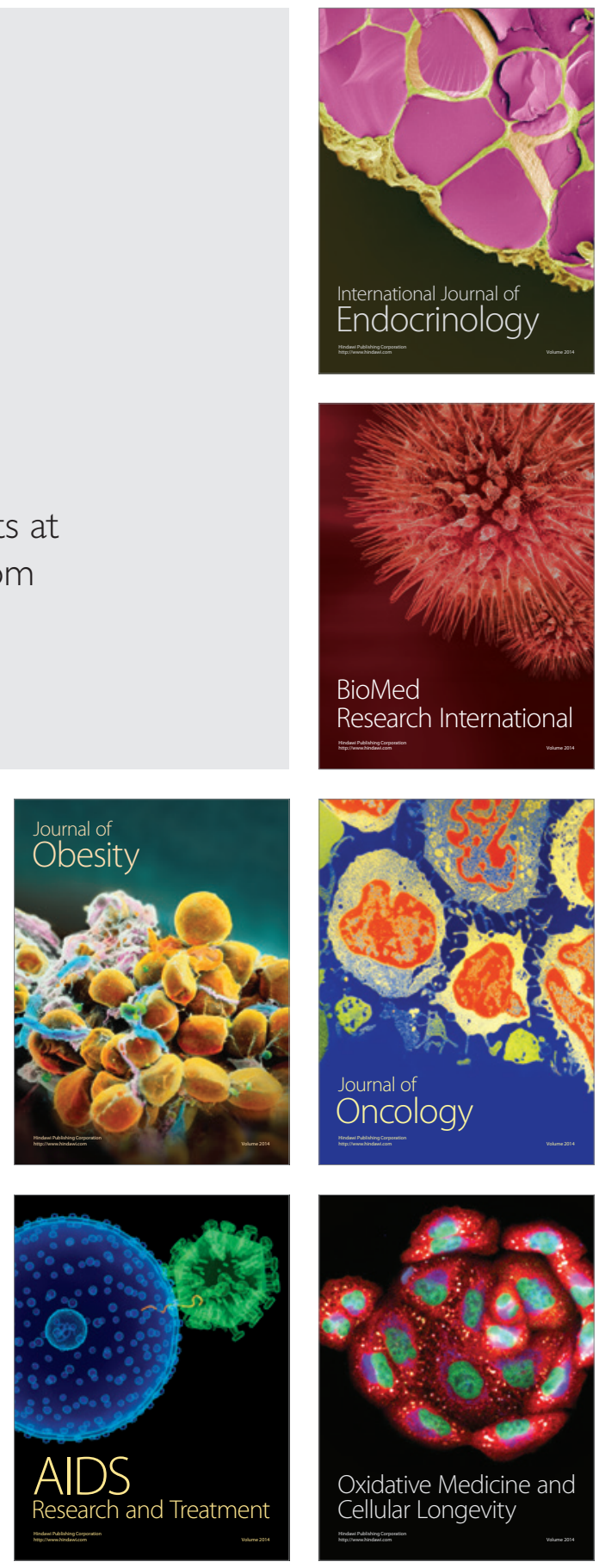